\title{
Study on Workability Compensation Laws of Concrete with Different Strength Grades
}

\author{
Xu Jun ${ }^{1,2, *}$, Liu Dan ${ }^{1,2}$, Zhan Yijian ${ }^{1,2}$ \\ ${ }^{1}$ Shanghai Construction Group Co., Ltd, Shanghai 200080, China \\ ${ }^{2}$ Shanghai Engineering Research Center of Mega Structuare High Performance Concrete
}

\begin{abstract}
This paper, by adopting the reverse mixing compensation technique of the admixtures, deals with the rules of how the secondary compensation mechanism of admixtures affects the recovery of concrete workability under conditions with different strength grades and different mix ratio designs, reveals the mechanism of how to adjust and control the concrete workability, and sets up the workability compensation law equation of $\mathrm{C} 30-\mathrm{C} 60$ concrete mixture based on average fit curve.
\end{abstract}

\section{Introduction}

Along with the rapid development of concrete mix ratio design technology in modern society, especially the introduction of multicomponent composite mineral admixtures and high-performance admixtures, the concrete workability, especially the gradual loss in slump, also varies accordingly. The study shows that in addition to being affected by the equipment performance, concrete pumping construction also depends on the stability of concrete quality to a great extent, particularly the ability to maintain working performance, namely, the gradual loss law in slump[1]. According to the engineering practices, slump loss can be influenced by many factors, including physical and chemical parameters of sands, aggregated rocks, cements, admixtures and other materials mixed in the concrete, mix ratio and environmental conditions[2]. Meanwhile ready-mixed concrete delivered from manufacturers, due to changes of ambient air temperature, evaporation of water, water absorption of aggregates, transportation, standby time and other influencing factors during the transportation, will also suffer from gradual loss of fluidity to different degrees. As a result, the workability of concrete to be pumped upon being delivered to the pumping construction site will dramatically decrease.

For this purpose, numerous scholars have been studying how to control the gradual loss of concrete workability via adding admixtures. Zhong Mingyun[3], Zhou Youbin[4], Che Wenxiu[5], Sheng Xiyou[6], Zhao $\mathrm{Su}[7]$, et al. have achieved certain achievements in adjusting the slump loss of concrete via preparing slowrelease slump-retaining type water-reducing admixtures with different molecular structures; Wang Jianhua[8], Zeng Xiaoxing[9], et al. apply slow-release slumpretaining type polycarboxylate water reducing admixtures to achieve the purpose of slowing down and retaining the slump of cement mortar and concrete, but note that the dosage of admixtures should be strictly controlled during the use, otherwise, it may result in concrete disintegration, bleeding and affect the successful pumping construction. According to the study of Chen Xinxiu et al.[2], slow release should be controlled within a reasonable scope in order to prevent the negative effects caused by too powerful slow release function.

In order to prevent problems concerned the adaptability and dosage control of different slow-release slump-retaining type admixtures, on-site constructors usually adjust the workability of ready-mixed concrete delivered to the construction site by adopting the explicitly banned secondary watering method based on the personal experience or preference, while, such method, in addition to resulting in concrete disintegration, bleeding, and then lead to pipe blocking, bursting and other engineering accidents, will also undermine the mechanical strength of concrete to a certain degree, and form potential quality hazards[10]. Therefore, this paper, by adopting the reverse mixing compensation technique of the admixtures, deals with the rules of how the secondary compensation mechanism of admixtures affects the recovery of concrete workability under conditions with different strength grades and different mix ratio designs, reveals the mechanism of how to adjust and control the concrete workability, and sets up the big data-based concrete workability compensation equation, which will serve as the theoretical guidance for compensating and recovering concrete workability loss, and meet the demands of pumping construction.

\section{Raw Materials and Mix Ratio Design}

\footnotetext{
*Corresponding author: xujun0504@126.com
} 


\subsection{Experimental materials}

"Conch brand" P.O.42.5 and P.II 52.5 high-performance cements produced by Anhui Tongling Conch Cement Co., Ltd. are selected as cements for test; Huaneng Grade II fly ash is selected as ash fly for test; S95 mineral powder is selected as mineral power for test; sands for test are natural river sands, medium sands, with the fineness modulus being $2.69 ; 5-25 \mathrm{~mm}$ continuously graded aggregates from Yangzhou are selected as aggregates for test, with small crush index, mud content and less elongated and flaky particles; tap water is selected for test. Furthermore, select Master intermediate-acting Type 301 admixture and Efficient
Type 8325 admixture are selected according to concretes with different strength grades respectively, with the solid content being $13 \%$ and $17 \%$ accordingly.

\subsection{Mix ratio design of concrete}

This paper conducts research on concretes with 6 different strength grades, including C30, C35, C40, C45, $\mathrm{C} 50$ and $\mathrm{C} 60$, and proceeds 5 kinds of mix ratio design on mixing dosage of cementing materials, water-binder ratio, sand ratio and other key parameters of concrete at each strength grade, respectively marked as $1 \#-5 \#$ mix ratio, with the design interval as shown in Table 1.

\begin{tabular}{|c|c|c|c|c|c|c|}
\multicolumn{1}{c}{ Table 1. Mix Ratio Design of Concrete with Different Strength Grades. } \\
\hline Type & C30 & C35 & C40 & C45 & C50 & C60 \\
\hline $\begin{array}{c}\text { Water-binder } \\
\text { ratio }\end{array}$ & $0.41-0.45$ & $0.43-0.47$ & $0.40-0.30$ & $0.27-0.30$ & $0.26-0.28$ & $0.2-0.22$ \\
\hline Cement & $195-205$ & $225-228$ & $228-245$ & $265-283$ & $280-295$ & $320-385$ \\
\hline Fly ash & $62-70$ & $75-65$ & $69-76$ & $87-65$ & $86-77$ & $85-63$ \\
\hline Mineral powder & $98-85$ & $95-75$ & $117-105$ & $105-95$ & $105-80$ & $128-79$ \\
\hline Sand ratio /\% & $44-45$ & $43.8-44$ & $43-42.6$ & $41.7-44.5$ & $42.6-42.3$ & $44-41$ \\
\hline Sand & $793-840$ & $790-809$ & $764-758$ & $739-810$ & $749-766$ & $755-703$ \\
\hline Aggregate & $1009-1020$ & $1015-1020$ & $1013-1020$ & $1034-1009$ & $1010-1044$ & $979-1012$ \\
\hline Water & $146-162$ & $120-173$ & $165-128$ & $122.5-133$ & $122.5-126.6$ & $112-116$ \\
\hline Admixture & $4.62-3.6$ & $3.14-5.52$ & $5.8-4.26$ & $4.32-4.11$ & $2.21-2.77$ & $5.33-5.09$ \\
\hline
\end{tabular}

\section{Test Methods}

This experimental study can be divided into three parts. The first part is to select the form of concrete workability compensation equation; the second part is to study the concrete workability compensation law, and the third part is to determine concrete workability compensation equation of concrete with different strength grades based on average fit curve.

The performance test can be split into two stages: the first stage is to test the initial slump and compressive strength performance of freshly mixed concrete with different strength grades, and the second stage is to test the secondary compensation performance of concrete admixtures after $3.5 \mathrm{~h}$ gradual loss. The freshly mixed concrete is mixed by the horizontal-shaft concrete mixer at once, and the test on its working performance shall refer to Test Method for Fluidity of Cement Mortar (GB/T 2419-2005), while the test on compressive strength Method of Testing Cements -Determination of Strength (ISO Method) (GB/T 17671-1999).

\section{Test Results and Analysis}

For the prepared C30-C60 freshly mixed concrete mixture, test its initial slump index value via applying the slump cone, and measure its compressive strength at 28d, with the test results as shown in Table 2.
Table 2. Test Results of C30-C60 Concrete Performance.

\begin{tabular}{|c|c|c|}
\hline $\begin{array}{c}\text { Strength } \\
\text { grade }\end{array}$ & Initial slump/mm & Compressive strength/MPa \\
\hline $\begin{array}{c}\text { C30 } \\
(1 \# \sim 5 \#)\end{array}$ & $190 / 140 / 160 / 180 / 185$ & $31.5 / 31.3 / 30.7 / 30.2 / 31.8$ \\
\hline $\begin{array}{c}\text { C35 } \\
(1 \# \sim 5 \#)\end{array}$ & $180 / 200 / 160 / 140 / 155$ & $36.2 / 36.5 / 35.9 / 36.8 / 35.2$ \\
\hline $\begin{array}{c}\text { C40 } \\
(1 \# \sim 5 \#)\end{array}$ & $230 / 180 / 190 / 200 / 170$ & $39.8 / 41.3 / 41.7 / 40.6 / 39.7$ \\
\hline $\begin{array}{c}\text { C45 } \\
(1 \# \sim 5 \#)\end{array}$ & $180 / 220 / 175 / 200 / 230$ & $45.7 / 45.8 / 45.2 / 46.4 / 46.3$ \\
\hline $\begin{array}{c}\text { C50 } \\
(1 \# \sim 5 \#)\end{array}$ & $210 / 190 / 180 / 165 / 220$ & $52.1 / 51.6 / 50.9 / 51.8 / 52.1$ \\
\hline $\begin{array}{c}\text { C60 } \\
(1 \# \sim 5 \#)\end{array}$ & $230 / 190 / 185 / 170 / 160$ & $58.8 / 59.6 / 61.5 / 62.0 / 60.7$ \\
\hline
\end{tabular}

Usually, concrete mixing plant has certain radiation radius, and the transit time from the moment when the concrete mixture is delivered out of the mixing plant to the actual project site for pumping and casting is generally not more than $3 \mathrm{~h}$. In view of this, this paper properly extends the concrete mixture's gradual loss, sets it to $3.5 \mathrm{~h}$, and covers it to prevent moisture loss in order to tackle the possible changes in the engineering practice. Upon the occurrence of slump loss over time, reverse mixing method is adopted to gradually restore the working performance of concrete mixture until it returns to the initial ex-factory slump, and to explore the compensation and recovery laws of concrete workability.

\subsection{Selection of compensation law fit curve equation}

In order to more accurately express the mapping relationship between concrete slump and secondary compensation dosage of admixtures, it is particularly critical to select a scientific and reasonable fit curve. In 
this paper, C30 concrete mixture under 5 different mix ratio design conditions is taken as the representative object for in-depth discussion. The test results of secondary compensation and recovery of C30 concrete mixture (1\#-5\#) after gradual loss in slump are shown in Table 3.

Table 3. Compensation and Recovery Data of C30 Concrete Suffering Gradual Loss in Slump.

\begin{tabular}{|c|c|c|c|c|c|}
\hline No. of mix ratio & $1 \#$ & $2 \#$ & $3 \#$ & $4 \#$ & $5 \#$ \\
\hline $\begin{array}{c}\text { Secondary compensation } \\
\text { ratio of admixtures } \%\end{array}$ & $\begin{array}{c}0 / 0.1 / 0.2 / \\
0.3 / 0.35\end{array}$ & $\begin{array}{c}0 / 0.1 / 0.15 / \\
0.25 / 0.3\end{array}$ & $\begin{array}{c}0 / 0.15 / 0.2 / \\
0.3 / 0.35\end{array}$ & $\begin{array}{c}0 / 0.1 / 0.2 / \\
0.3 / 0.4\end{array}$ & $\begin{array}{c}0 / 0.1 / 0.15 / \\
0.25 / 0.3\end{array}$ \\
\hline Slump/mm & $\begin{array}{c}75 / 125 / 160 / \\
180 / 190\end{array}$ & $\begin{array}{c}50 / 75 / 90 / \\
125 / 140\end{array}$ & $\begin{array}{c}60 / 100 / 125 / \\
145 / 160\end{array}$ & $\begin{array}{c}80 / 130 / 145 / \\
170 / 180\end{array}$ & $\begin{array}{c}80 / 120 / 155 / \\
170 / 185\end{array}$ \\
\hline Gradual loss in slump/mm & $115 / 65 / 30 /$ & $\begin{array}{c}90 / 65 / 50 / \\
15 / 0\end{array}$ & $\begin{array}{c}100 / 60 / 35 / \\
15 / 0\end{array}$ & $\begin{array}{c}100 / 50 / 35 / \\
10 / 0\end{array}$ & $\begin{array}{c}105 / 65 / 30 / \\
15 / 0\end{array}$ \\
\hline $\begin{array}{c}\text { Compensation ratio of } \\
\text { admixtures/\% }\end{array}$ & $\begin{array}{c}0.35 / 0.25 / 0.15 / \\
0.05 / 0\end{array}$ & $\begin{array}{c}0.3 / 0.2 / 0.15 / \\
0.05 / 0\end{array}$ & $\begin{array}{c}0.35 / 0.2 / 0.15 / \\
0.05 / 0\end{array}$ & $\begin{array}{c}0.4 / 0.3 / 0.2 / \\
0.1 / 0\end{array}$ & $\begin{array}{c}0.3 / 0.2 / 0.15 / \\
0.05 / 0\end{array}$ \\
\hline
\end{tabular}

According to relevant literature and practical experience, there are mainly two types of equations used to express the compensation laws of concrete workability: the first type is parabolic equation: $f(x)=$ $a x^{2}+b x+c$; the second type is the hyperbola equation: $f(x)=\mathrm{x} /(a x+b)$. Wherein, $f(x)$ refers to the compensation ratio of concrete admixtures, expressed in $\% ; x$ refers to concrete slump loss, expressed in $\mathrm{mm}$.

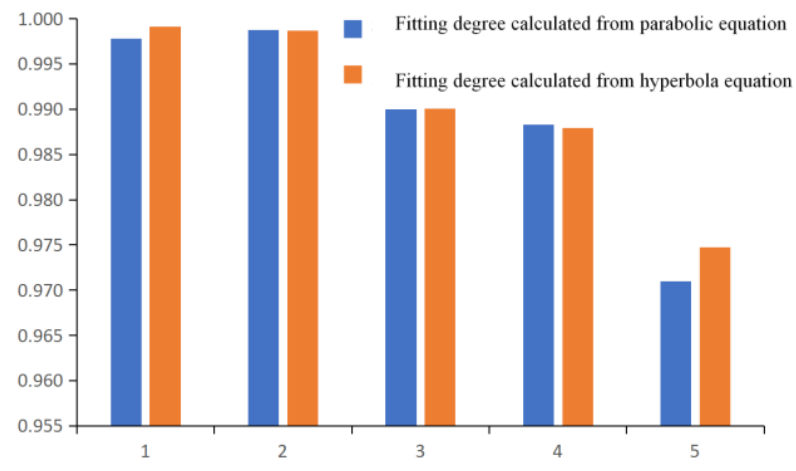

Fig.1. Comparison of Fitting Degree Calculated from Two Types of Fitting Equations.
In this paper, these two equations are respectively used to fit the compensation and recovery data of C30 concrete mixture (\#1-\#5) suffering gradual loss in slump. The comparative analysis of fitting degree is shown in Figure 1.

As shown in Figure 1, compared with the parabolic equation, the fitting degree calculated from the hyperbolic equation is higher as a whole, all above $97.5 \%$, and the expression of compensation laws is more accurate.

\subsection{Experimental study on the compensation laws}

The paper carries out the secondary compensation and recovery tests of concrete mixtures suffering gradual loss in slump by taking $\mathrm{C} 30-\mathrm{C} 60$ concrete mixtures (1\#-5\#) under 5 different mix ratio design conditions as the objects, with the results of representative tests (1\#) shown in Table 4.

Table 4. Mapping Relationship between Gradual Loss in Slump of C30-C60 Concrete and Compensation Ratio of Admixtures.

\begin{tabular}{|c|c|c|c|c|c|c|}
\hline Type & $\mathrm{C} 30$ & $\mathrm{C} 35$ & $\mathrm{C} 40$ & $\mathrm{C} 45$ & $\mathrm{C} 50$ & $\mathrm{C} 60$ \\
\hline $\begin{array}{c}\text { Secondary compensation } \\
\text { ratio of admixtures } \%\end{array}$ & $\begin{array}{c}0 / 0.1 / 0.2 / \\
0.3 / 0.35\end{array}$ & $\begin{array}{c}0 / 0.1 / 0.15 / \\
0.2 / 0.25\end{array}$ & $\begin{array}{c}0 / 0.1 / 0.2 / \\
0.25 / 0.3\end{array}$ & $\begin{array}{c}0 / 0.1 / \\
0.2 / 0.3\end{array}$ & $\begin{array}{c}0 / 0.1 / 0.15 / \\
0.2 / 0.25\end{array}$ & $\begin{array}{c}0 / 0.1 / 0.15 / \\
0.2 / 0.25\end{array}$ \\
\hline Slump/mm & $\begin{array}{c}75 / 125 / 160 / \\
180 / 190\end{array}$ & $\begin{array}{c}50 / 80 / 120 / \\
150 / 185\end{array}$ & $\begin{array}{c}130 / 180 / 200 / \\
215 / 225\end{array}$ & $\begin{array}{c}60 / 130 / \\
160 / 185\end{array}$ & $\begin{array}{c}40 / 100 / 150 / \\
190 / 210\end{array}$ & $\begin{array}{c}80 / 175 / 205 / \\
220 / 230\end{array}$ \\
\hline Gradual loss in slump/mm & $\begin{array}{c}115 / 65 / 30 / \\
10 / 0\end{array}$ & $\begin{array}{c}130 / 100 / 60 / \\
30 / 0\end{array}$ & $\begin{array}{c}100 / 50 / 30 / \\
15 / 0\end{array}$ & $\begin{array}{c}120 / 50 / \\
20 / 0\end{array}$ & $\begin{array}{c}170 / 110 / 60 / \\
20 / 0\end{array}$ & $\begin{array}{c}150 / 55 / 25 / \\
10 / 0\end{array}$ \\
\hline $\begin{array}{c}\text { Compensation ratio of } \\
\text { admixtures/\% }\end{array}$ & $\begin{array}{c}0.35 / 0.25 / 0.15 / \\
0.05 / 0\end{array}$ & $\begin{array}{c}0.25 / 0.15 / 0.1 / \\
0.05 / 0\end{array}$ & $\begin{array}{c}0.3 / 0.2 / 0.1 / \\
0.05 / 0\end{array}$ & $\begin{array}{c}0.3 / 0.2 / \\
0.1 / 0\end{array}$ & $\begin{array}{c}0.25 / 0.15 / 0.1 / \\
0.05 / 0\end{array}$ & $\begin{array}{c}0.25 / 0.15 / 0.1 / \\
0.05 / 0\end{array}$ \\
\hline
\end{tabular}

Based on the above test data, the hyperbolic equation is used for fitting analysis to obtain the compensation and recovery law curve of C30-C60 concrete mixture (1\#-5\#) suffering gradual loss in slump under different mix ratio design conditions, as shown in Figure 2. 


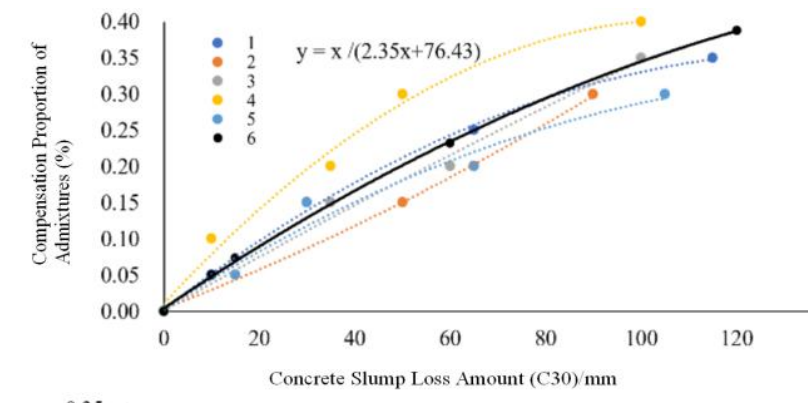

As shown in Figure 2, the slump loss of concrete at the same strength grade under different mix ratio design conditions (1\#-5\#) occurs at different speed, and their compensation laws vary to a certain degree. However, such difference is mainly caused by different mix ratio design conditions of concrete, and there are no obvious characteristics or laws available.

At the same time, the gradual loss in slump and their corresponding compensation laws of concrete mixtures with different strength grades vary largely, which is closely related to concrete admixtures. In general, the gradual loss in slump of concrete mixtures with low strength grade occurs at relatively fast speed and relatively large amount of loss, in contrast, the gradual loss in slump of concrete mixtures with high strength grade occurs at relatively slow speed and relatively small amount of loss.

The difference of workability compensation and recovery effects of concrete mixtures with different strength grades can be attributed to internal and external factors. The main internal factor is because the different dosage of binding materials and water-cement ratio in the mix ratio design of concrete with different strength grades will cause the different hydration rate, thus affecting the slump loss and workability recovery effect. The main external factor is the influence of different performance of admixtures: for concrete with low strength grade, intermediate-acting polycarboxylate admixtures are often added, with poor effect of releasing free water, as a result, the relatively low secondary compensation amount of admixtures has no obvious effect on the recovery of its workability; for concrete with high strength grade, high-range polycarboxylate admixture will be added, with better performance of releasing free water, as a result, relatively low secondary compensation amount of admixtures can recover its workability to the initial state.

\subsection{Determine the Workability Compensation Equation of Concrete with Different Strength Grade Based on Average Fit Curve}

Based on the compensation law curve of C30-C60 concrete suffering gradual loss in slump (1\#-5\#), fir the average values to obtain the average fit curve of compensation and recovery of $\mathrm{C} 30-\mathrm{C} 60$ concrete suffering gradual loss in slump (6\# black curve), as shown in Figure 2.

Based on 1\#-5\# fit curves, select several feature points of slump loss to obtain the compensation ratio of concrete admixture on corresponding fit curve, and calculate its discrete coefficient to carry out the discrete analysis of average fit curve. In this paper, C30 concrete is taken as the representative object, and the analysis data of discrete degree on the average fit curve is shown in Table 5.

As shown in Table 5, the discrete degree of fit data points on the average fit curve $(6 \#)$ and the original 5 groups (1\#-5\#) is all within the range of $0-0.42$, which is of representative significance. Moreover, with the increase of slump loss and proportion of required 
admixtures, the smaller the discrete degree of the average fit curve is, the more remarkable the representative significance is.

Table 5. Discrete Analysis of C 30 Concrete (1\#-5\#)

Workability Compensation Average Fit Curve.

\begin{tabular}{|c|c|c|c|}
\hline$x / \mathrm{mm}$ & $y / \%$ & $\begin{array}{c}\text { Standard } \\
\text { deviation }\end{array}$ & $\begin{array}{c}\text { Discrete } \\
\text { degree }\end{array}$ \\
\hline 120 & $0.36 / 0.43 / 0.41 / 0.43 / 0.32$ & 0.05 & 0.13 \\
\hline 60 & $0.24 / 0.19 / 0.22 / 0.31 / 0.20$ & 0.05 & 0.21 \\
\hline 15 & $0.08 / 0.04 / 0.06 / 0.12 / 0.07$ & 0.03 & 0.40 \\
\hline 10 & $0.05 / 0.03 / 0.04 / 0.08 / 0.05$ & 0.02 & 0.42 \\
\hline 0 & $0 / 0 / 0 / 0 / 0$ & 0 & 0 \\
\hline
\end{tabular}

Similarly, according to the discrete analysis, it finds that the discrete degree of $\mathrm{C} 35$ concrete mixture workability compensation law average fit curve is within 0-0.46, 0-0.25 for C40 concrete, $0-0.13$ for C45 concrete, 0-0.26 for C50 concrete, 0-0.19 for C60 concrete. Namely, the discrete degree of all concrete mixtures is below 1.0, which can be classified into low difference level. Therefore, C30-C60 concrete mixture workability compensation law average fit curve is of representative significance. It can better represent the compensation and recovery law of $\mathrm{C} 30-\mathrm{C} 60$ concrete suffering gradual loss in slump under different mix ratio design conditions, and the compensation and recovery average fit curve equation can be adopted as the recommended equation, as shown in Table 6.

Table 6. C30-C60 Concrete Workability Compensation

Equation Based on Average Fit Curve.

\begin{tabular}{|c|c|c|c|c|}
\hline \multirow{3}{*}{ Curve formula } & \multirow{2}{*}{ Type } & \multicolumn{2}{|c|}{ Equation coefficient } & \multirow{2}{*}{$R^{2}$} \\
\cline { 3 - 4 } & & $A$ & $b$ & \\
\hline \multirow{5}{*}{$f(x)=x /(a x+b)$} & $\mathrm{C} 30$ & 2.3500 & 76.4 & 0.9842 \\
\cline { 2 - 5 } & $\mathrm{C} 35$ & 1.0880 & 478.0 & 0.9770 \\
\cline { 2 - 5 } & $\mathrm{C} 40$ & 1.9610 & 196.1 & 0.9772 \\
\cline { 2 - 5 } & $\mathrm{C} 45$ & 0.0189 & 419.6 & 0.9842 \\
\cline { 2 - 5 } & $\mathrm{C} 50$ & -1.0850 & 997.1 & 0.9746 \\
\cline { 2 - 5 } & $\mathrm{C} 60$ & 4.0470 & 131.6 & 0.9922 \\
\hline
\end{tabular}

\section{Conclusions}

(1) The concrete with low strength grade is featured with fast rate of gradual loss in slump and relatively large amount of loss, and the relatively low secondary compensation amount of admixtures has no obvious effect on the recovery of its workability. The concrete with high strength grade is featured with a relatively slow rate of gradual loss in slump and a relatively small amount of loss, and its initial workability can be recovered by the relatively low secondary compensation amount of the admixtures.

(2) Compared with the parabolic equation, the overall fitting degree calculated via hyperbolic equation is much higher, being over $97.5 \%$, which can better express the concrete workability compensation laws.

(3) The concrete workability compensation law average fit curve is featured with relatively low discrete degree, and smaller errors, can better represent the compensation laws of $\mathrm{C} 30-\mathrm{C} 60$ concrete suffering gradual loss in slump under different mix ratio design conditions.

(4) Establish C30-C60 concrete mixture workability compensation law equation based on the average fit curve, which can serve as the theoretical guidance for compensating and recovering concrete workability loss and ensure the construction quality.

\section{Acknowledgments}

This research was financially supported by the National Key R\&D Program of China (Project No. 51878404), the Shanghai Committee of Science and Technology (No. 18DZ2282600) and Shanghai Construction Group Co., Ltd (Project No. 17YJKF-02).

\section{References}

1. Lu Y.X. (2011) Preparation of C50 high performance pumping concrete. China Concrete and Cement Products, 05: 22-25.

2. Chen X.X., Ding X.C., Liao J.Q. ,et. al. (2014) Research progress of slow release polycarboxylate superplasticizer. Science and Technology Innovation Guide, 11(07): 5-7.

3. Zhong M.Y., Fan Z., Li W.K., He B., et. al. (2019) Experimental study on workability and mechanical properties of high mud content manufactured sand concrete with an organic admixture. China Concrete and Cement Products, 01: 26-30.

4. Zhou Y.B., Xiao Y.F. (2020) Synthesis and application of slow release polycarboxylate superplasticizer. Jiangxi Building Materials, 03: 21$22+24$.

5. Che W.X., Li X.N., Li T., et. al. (2017) Application of super slow release polycarboxylate superplasticizer in different types of concrete. New Building Materials, 44(09): 71-73.

6. Sheng X.Y., Wang W.J., He K., et. al. (2010) Development and application of slow release polycarboxylate superplasticizer. Concretes, 06: 6870.

7. Zhao S, Fu E.K., Li M., et. al. (2014) Preparation of high performance slow release polycarboxylate superplasticizer. Concretes, 07: 89-92.

8. Wang J.H., Zhou P.Y. (2009) Research and Application of Slow Release Polycarboxylate Superplasticizer. In: Seminar on new Technology and Equipment of Concrete Admixture. Beijing. pp. 82-85.

9. Zeng X.X., Guo Z.J., Li X.L. (2018) Study on Application of slow release and slump retaining polycarboxylate superplasticizer in concrete. New Building Materials, 45(03): 87-89.

10. Li D.C., Li H.Z., Xu Q.L., et. al. Project management of ready mixed concrete in oilfield surface engineering. Surface Engineering of Oil and Gas Field, 31(09): 79. 